\title{
Body composition changes in acute stroke by type of feeding regimen
}

Mohannad W Kafri ${ }^{1,2}$, John F Potter ${ }^{3,4}$, Phyo Kyaw Myint ${ }^{1,3,4}$

${ }^{1}$ Epidemiology Group, School of Medicine \& Dentistry, Institute of Applied Health Sciences, University of Aberdeen, Scotland, AB25 2ZD, United Kingdom

${ }^{2}$ Department of Nutrition and Dietetic, Birzeit University, PO Box 14, Birzeit West Bank, Palestine

${ }^{3}$ Norwich Medical School, University of East Anglia, Norwich Research Park, Norwich, NR4 7TJ, United Kingdom

${ }^{4}$ Stroke Research Group, Academic Department of Medicine for the Elderly, Norfolk and Norwich University Hospital, Norwich, NR4 7UY, United Kingdom

Mohannad W Kafri

Associate Professor in Nutrition \& Dietetics

John F Potter

Professor of Ageing \& Stroke Medicine

Phyo Kyaw Myint

Professor of Medicine of Old Age

\section{Correspondence to:}

Professor Phyo Kyaw Myint

Room 4.013, Polwarth Building

School of Medicine \& Dentistry

University of Aberdeen

Foresterhill, Aberdeen

AB25 2 ZD

Scotland, UK

Tel: +44 (0) 1224437841

Fax: +44 (0) 1224437911

Mail to: phyo.myint@abdn.ac.uk 
Key words:

- Stroke

- Body composition

- Multi-frequency bioelectrical impedance analysis

- Nutrition

- Feeding regimen

- Dysphagia 


\section{Dear Sir,}

Dysphagia is very common in the initial weeks following acute stroke with quoted prevalence rates of between $37 \%$ and $78 \%$ (1), and can lead to poor dietary intake and associated with an increased risk of mortality in stroke (2). Moreover, weight loss and malnutrition are well documented long term effects after stroke (3). However, attempts to intervene nutritionally do not appear to show significant benefits as evidenced in the multicentre FOOD trial $(4,5)$. This indicates a better understanding of the changes in nutritional status following stroke are necessary.

Ischaemic stroke patients admitted to an acute unit were recruited in an observational study and their body compositions measured using Multi-Frequency Bioelectrical Impedance Analysis (MF-BIA) on admission and discharge along with demographic, anthropometric, and biochemical parameters. The ethical approval was obtained from the Cambridgeshire (I) Research Ethics Committee (Ref: 10/H0304/18). Consenting patients admitted within 48 hours of symptom onset were included in the study if they were age 17 years or over and admitted with a newly diagnosed ischaemic stroke (either first or recurrent) confirmed by clinical features and neuro-radiological evidence. Exclusion criteria included very severe stroke (where palliation was the only option or National Institute of Health Stroke Scale (NIHSS) $\geq 30$ (http://www.ninds.nih.gov/doctors/NIH Stroke Scale.pdf), people with life expectancy of less than 3 months prior to the event, and those with potential confounding conditions that might have been masking/exaggerating the effect of post stroke nutrition on body composition changes (e.g. advanced cancer, end stage chronic diseases). 
The feeding method was assessed at the time of study enrolment. The MF-BIA measurements were taken in duplicate, less than one minute apart without replacing the electrodes and the mean values were used in the analysis. MF-BIA measurements were carried out twice; one at baseline (within 48 hours of admission) and repeated at the time of discharge (usually within 6-48 hours of discharge). From BIA measures data on fat free mass, fat mass, protein mass, muscle mass, and body cell mass (all in kg) were collected. Type of feeding regimen was classified according to speech and language therapist's assessment and recommended method; nil-by mouth, normal feeding and modified diet (soft-mashed/pureed) with further classification as nonnormal feeding and normal feeding regimen for analytical purpose. Mean fat free mass (FFM), fat mass (FM), and protein mass (PM) changes and daily mean differences between admission and discharge were compared between non-normal (soft mashed/pureed and nil-by-mouth (NBM)) vs. normal feeding and between soft mashed/pureed diet vs. NBM.

A total of 40 patients (55\% men), mean age $69.8 \pm 10.5$ years with ischaemic stroke were recruited with a mean National Institute of Health Stroke Scale (NIHSS) 5.0 (median 3, range 1-21). For FFM, FM, and BCM data were available in 40 patients and for PM and MM data were available for 39 patients. The majority (42.5\%) of the participants had a lacunar infarct, and had mild to moderately severe stroke symptoms NIHSS range $<10$. Hospital length of stay was 4.1 (SD 4.2; median 3) days. At baseline BMI values for NBM, soft mashed/puree diet and normal oral diet were 23.9, 28.4 and $27.0 \mathrm{~kg} / \mathrm{m}^{2}$, respectively. As a group, BMI increased over the study period but it was not significant $(\mathrm{p}=0.20$; mean difference +0.22 (95\%CI:0.10-0.60). Descriptive analysis of the data suggested no statistically significant (two-sided $\mathrm{p}<0.05$ as significant 
level) body composition losses or gains between soft-mashed/pureed and nil-by mouth (NBM)) vs. normal feeding and between soft mashed/pureed diet vs. NBM groups between admission and discharge (data not shown). However, the higher proportion of participants (82\%) had muscle mass loss and this was significant $(\mathrm{p}=0.05)$ (Table 1$)$.

To our knowledge this is the first study which attempted to understand the immediate changes in body composition following acute stroke setting using a validated, portable, multi-component model device. The main finding of the study is that as expected more stroke patients with difficulties in swallowing indicated by requirement of modified diet or NBM feeding regimen lost protein and muscle mass during their hospital stay. The study however is limited by the relatively small sample size and short duration of follow-up between measures, which may contributed to the fact that we did not find any statistically significant changes except for a marginal decrease in protein mass observed in the whole sample. However we observed significant muscle mass loss and statically significant FFM loss in the majority of patients (29/40).

Fat free mass, protein mass, muscle mass losses and fat mass gains observed in modified diet and NBM groups can be related to the severity of their condition rendering them bedridden, with a heightened stress response and making such body composition changes inevitable in line with existing evidence. Being inactive and bedridden can contribute to lean tissue mass losses (6), and the stress response evident in increased serum cortisol level in acute stroke patients (7) may explain the loss in lean body tissue (8). In addition, the increased fat mass can be related to their inactive bedridden state. Their use of active tissue such as muscles is very minimal which may result in fat tissue accumulation and active tissue loss $(9,10)$. 
We have shown that patients with stroke on modified diet and NBM feeding regimen had consistent body composition changes in negative direction with the majority experiencing fat free mass loss, fat mass gain, and muscle mass, and protein mass losses. Whilst patients with NBM regimen are likely to be switched to NGT feeding regimen, this if happened would only attenuate the results. Between admission and discharge measurements was not long enough to observe statistically significant changes across all examined body composition indices.

Whilst our study showed that supported feeding may not compensate the impaired energy supply in acute stroke patients, it may help in designing future targeted interventions of nutritional care in acute stroke. This study also provides some normative data of body composition changes by different feeding regimens to help future sample size calculations and to determine minimally clinically significant differences for nutritional research in stroke. Further research is also required in clinical trial setting to understand the impact of targeted intervention on body composition changes in acute stroke. 


\section{References}

1. Martino R, Foley N, Bhogal S, Diamant N, Speechley M, Teasell R.

Dysphagia after stroke: incidence, diagnosis, and pulmonary complications. Stroke. 2005;36:2756-2763.

2. Guyomard V, Fulcher RA, Redmayne O, Metcalf AK, Potter JF, Myint PK. Effect of dysphasia and dysphagia on inpatient mortality and hospital length of stay: a database study. J Am Geriatr Soc. 2009;57:2101-6.

3. Jonsson A-C, Lindgren I, Norrving B, Lindgren A. Weight loss after stroke: a population-based study from the Lund Stroke Register. Stroke 2008;39:918-923.

4. Hamidon BB, Abdullah SA, Zawawi MF, Sukumar N, Aminuddin A, Raymond AA. A prospective comparison of percutaneous endoscopic gastrostomy and nasogastric tube feeding in patients with acute dysphagic stroke. Medical Journal of Malaysia. 2006;61:59-66.

5. Norton B, Homer-Ward M, Donnelly MT, Long RG, Holmes GK. A randomised prospective comparison of percutaneous endoscopic gastrostomy and nasogastric tube feeding after acute dysphagic stroke. BMJ 1996;312:13-16.

6. Ferrando AA, Lane HW, Stuart CA, Davis-Street J, Wolfe RR. Prolonged bed rest decreases skeletal muscle and whole body protein synthesis. American Journal of Physiology - Endocrinology and Metabolism 1996;270:E627-E33.

7. Davalos A, Ricart W, Gonzalez-Huix F, Soler S, Marrugat J, Molins A, et al. Effect of malnutrition after acute stroke on clinical outcome. Stroke1996;27:10281032.

8. Ferrando AA, Stuart CA, Sheffield-Moorem, Wolferr. Inactivity Amplifies the Catabolic Response of Skeletal Muscle to Cortisol. Journal of Clinical Endocrinology \& Metabolism 1999;84:3515-3521.

9. Gelfand RA, Matthews DE, Bier DM, Sherwin RS. Role of counterregulatory hormones in the catabolic response to stress. The Journal of Clinical Ivestigation1984;74:2238-2248.

10. Brillon DJ, Zheng B, Campbell RG, Matthews DE. Effect of cortisol on energy expenditure and amino acid metabolism in humans. American Journal of Physiology - Endocrinology And Metabolism 1995;268:E501-E513. 


\section{Acknowledgements}

We thank the participants of the study. We gratefully acknowledge the assistance of the Stroke Research Team and staff of acute stroke unit at the Norfolk and Norwich University Hospital. We would like to thank Dr Lee Hooper for her comments.

\section{Funding}

MWK received PhD Studentship Award from Faculty of Medicine and Health Sciences, University of East Anglia and was also partly funded by his employer Birzeit University, Palestine.

\section{Contribution}

MWK designed the study with input from JFP and PKM. MWK recruited the participants, collected data and analysed the data. MWK and PKM drafted the early versions of the manuscript. All authors contributed in the writing of the paper. MWK is the guarantor.

\section{Conflict of Interest}

None

\section{Disclosures}

MWK received funding from the European Hydration Institute.

JFP received funding from British Heart Foundation, Medical Research Council, National Institute of Health Research and Dunhill Medical Trust

PKM received funding from National Institute of Health Research and The Sir Halley Stewart Trust.

\section{Ethics}

The Cambridgeshire I Research Ethics Committee approved the study. 
Table 1: Stratified analyses of selected body composition mean daily changes for normal oral diet and modified diet and also nil-by-mouth (NBM) and non-NBM diet. Muscle mass loss was statistically significant in modified diet group.

\begin{tabular}{|c|c|c|c|c|c|c|c|}
\hline & $\begin{array}{l}\text { Participants } \\
\text { with body } \\
\text { composition } \\
\text { loss (\%) } \\
\end{array}$ & $\begin{array}{l}\text { Participants } \\
\text { with body } \\
\text { composition } \\
\text { gain (\%) }\end{array}$ & Admission (kg) & Discharge (kg) & $\begin{array}{l}\text { mean difference } \\
(95 \% \mathrm{CI}) \mathrm{kg}\end{array}$ & $\mathrm{p}$-value & $\begin{array}{l}\text { Change } \\
\text { rate } \mathrm{kg} / \text { day }\end{array}$ \\
\hline \multicolumn{8}{|c|}{ Normal diet vs. Modified diet } \\
\hline \multicolumn{8}{|c|}{ Fat Free Mass (kg) } \\
\hline Normal oral & $16(55 \%)$ & $13(45 \%)$ & $52.1(9.7)$ & $51.6(8.9)$ & $-0.5(-1.1$ to 0.3$)$ & 0.23 & $-0.4(1.4)$ \\
\hline Modified diet & $8(73 \%)$ & $3(27 \%)$ & $50.3(9.7)$ & $49.8(10.2)$ & $-0.4(-2.0$ to 1.2$)$ & 0.57 & $-0.4(0.9)$ \\
\hline \multicolumn{8}{|l|}{ Fat mass (kg) } \\
\hline Normal oral & $13(45 \%)$ & $16(55 \%)$ & $26.1(10.1)$ & $26.3(10.2)$ & $0.2(-0.7$ to 1.1$)$ & 0.66 & $0.3(1.6)$ \\
\hline Modified diet & $4(36 \%)$ & 7 (64\%) & $24.8(10.9)$ & $25.3(11.1)$ & 0.5 (-0.9 to 1.9$)$ & 0.44 & $0.4(0.9)$ \\
\hline \multicolumn{8}{|c|}{ Protein mass (kg)* } \\
\hline Normal oral & $18(64 \%)$ & $10(36 \%)$ & $7.5(2.8)$ & $7.3(3.0)$ & $-0.3(-0.9$ to 0.3$)$ & 0.32 & $-0.3(1.2)$ \\
\hline Modified diet & $9(82 \%)$ & $2(18 \%)$ & $7.3(3.1)$ & $6.3(2.7)$ & $-1.0(-2.0$ to 0.1$)$ & 0.07 & $-0.5(0.6)$ \\
\hline \multicolumn{8}{|c|}{ Body Cell Mass (kg) } \\
\hline Normal oral & 17 (59\%) & $12(41 \%)$ & $29.3(8.3)$ & $28.1(6.3)$ & $-1.2(-4.3$ to 1.8$)$ & 0.40 & $-1.8(6.4)$ \\
\hline Modified diet & 7 (64\%) & $4(36 \%)$ & $27.2(5.5)$ & $26.9(6.2)^{\$}$ & $-0.3(-1.5$ to 1.0$)$ & 0.64 & $-0.1(1.4)$ \\
\hline \multicolumn{8}{|c|}{ Muscle Mass (kg)* } \\
\hline Normal oral & $16(55 \%)$ & $12(45 \%)$ & $23.2(5.7)$ & 25.6(14.7) & $2.4(-3.4$ to 8.2$)$ & 0.40 & $0.4(5.2)$ \\
\hline Modified diet & 8 (73\%) & $3(27 \%)$ & 22.7 (5.9) & 21.5 (6.3) & $-1.2(-2.3$ to 0.0$)$ & 0.05 & $-0.5(1.1)$ \\
\hline \multicolumn{8}{|c|}{ Non-NBM vs. NBM } \\
\hline \multicolumn{8}{|c|}{ Fat Free Mass (kg) } \\
\hline NBM & $\begin{array}{l}19(54 \%) \\
5(100 \%)\end{array}$ & $\begin{array}{c}16(46 \%) \\
0(0 \%)\end{array}$ & $\begin{array}{l}52.1(9.9) \\
48.5(7.5)\end{array}$ & $\begin{array}{l}51.0(9.4) \\
46.6(7.3)\end{array}$ & $-1.9(-4.3$ to 0.5$)$ & $\begin{array}{l}0.45 \\
0.09\end{array}$ & $\begin{array}{l}-0.4(1.4) \\
-0.9(1.0)\end{array}$ \\
\hline
\end{tabular}


Fat mass (kg)

non-NBM

NBM

$16(46 \%)$

19 (54\%)

$26.6(10.2)$

$26.7(7.6)$

0.1 (-0.6 to 0.9$)$

0.74

$0.3(1.5)$

Protein mass (kg) ${ }^{\mathrm{a}}$

$1(20 \%)$

4 (80\%)

19.4 (7.8)

$20.8(8.2)$

1.4 (-1.8 to 4.6$)$

0.29

$0.8(1.1)$

non-NBM

NBM

$23(68 \%)$

$11(32 \%)$

$7.6(2.9)$

$7.2(2.9)$

$-0.4(-1.0$ to 0.1$)$

0.13

$-0.3(1.1)$

Body Cell Mass (kg)

non-NBM

$4(80 \%)$

$1(20 \%)$

$6.5(3.0)$

$5.6(2.8)$

-0.9 ( -2.1 to 0.4$)$

0.12

$-0.6(0.8)$

NBM

Muscle Mass (kg) ${ }^{\text {a }}$

non-NBM

$21(62 \%)$

$14(38 \%)$

$29.1(7.9)$

$28.0(6.4)$

$-1.1(-3.6$ to 1.3$)$

0. 35

$-1.5(6.3)$

$3(60 \%)$

2 (40\%)

26.0 (4.9)

26 (5.5)

0.01 (-2.8 to 3.0$)$

0.93

$-0.1(1.5)$

20 (59\%)

$14(41 \%)$

$23.3(5.8)$

25.1 (13.7)

$1.8(-2.9$ to 6.6$)$

0.44

0.3 (4.8)

NBM

$4(80 \%)$

$1(20 \%)$

21.5 (5.1)

20.1 (5.2)

$-1.4(-3.4$ to 0.6$)$

$0.12 \quad 0.9(1.2)$

${ }^{\mathrm{a}} \mathrm{N}=39$; the following variables were non-normally distributed: Body cell mass admission (normal oral diet), Body cell mass discharge (modified diet), Body cell mass admission (non-NBM), Body cell mass discharge (non-NBM), Muscle mass admission (normal oral diet), Muscle mass discharge (normal oral diet), Muscle mass discharge (modified diet), and Muscle mass discharge (non-NBM) 